\title{
ANALISIS TINGKAT PENERAPAN PROGRAM K3 BERDASARKAN BUILDING SAFETY INDEX (STUDI KASUS ASET GEDUNG BALE WIWITAN)
}

\author{
Monik Karlina $^{1}$, Aldelia Risnanda Sari ${ }^{2}$, Nabila Ayu Khairunnisa ${ }^{3}$, Nurlaila Fadjarwati ${ }^{4}$ \\ 1,2,3,4Program Studi Manajemen Aset, Politeknik Negeri Bandung, Jalan Gegerkalong Hilir, Kabupaten Bandung Barat \\ Email: monik.karlina.mas17@polban.ac.id
}

\begin{abstract}
Case study of Bale Wiwitan Building, Tasikmalaya. Bale Wiwitan is an asset of a government office building occupied by several Tasikmalaya Service Offices which are estimated to have a land area of 1.7 hectares and a building area of 2,089 $\mathrm{m}^{2}$. The building is a facility to support various activities of office employees, and each building asset must Occupational Health and Safety (OHS) standards to minimize risks. This study aims were to determine the level of implementation of the OHS program based on the Building Safety Index (BSI) on the Bale Wiwitan Tasikmalaya building assets. The research method was a survey method, with the technique of observation, interviews, questionnaires and literature study. Based on the results of the study, the level of implementation of the OHS program based on BSI obtained an average of 3.3. As such, it was good, as evidence and also by the condition of the building which was feasible, functions in accordance with BSI indicators, namely architecture, building service, and external environment.
\end{abstract}

Keywords: BSI, office building, OHS

\begin{abstract}
Abstrak
Studi kasus Gedung Bale Wiwitan, Tasikmalaya. Bale Wiwitan adalah aset gedung kantor pemerintahan yang ditempati oleh beberapa Kantor Dinas Tasikmalaya yang diperkirakan memiliki luas tanah 1,7 Ha dan luas bangunan $2.089 \mathrm{~m}^{2}$. Bangunan gedung merupakan suatu fasilitas untuk menunjang berbagai aktifitas kegiatan pegawai perkantoran, dan setiap aset bangunan harus memenuhi standar Kesehatan dan Keselamatan Kerja (K3) untuk meminimalisir risiko. Penelitian ini bertujuan untuk mengetahui tingkat penerapan program K3 berdasarkan Building Safety Index (BSI) pada aset gedung Bale Wiwitan Tasikmalaya. Metode penelitian yang digunakan adalah metode survei, dengan teknik observasi, wawancara, kuesioner dan studi pustaka. Berdasarkan hasil penelitian, tingkat penerapan program K3 berdasarkan BSI memperoleh rata-rata sebesar 3,35 dan dapat dikatakan baik, dibuktikan juga dengan kondisi bangunan gedung yang laik dan berfungsi sesuai dengan indikator BSI yaitu arsitektur, building service, dan external environment.
\end{abstract}

Kata Kunci : BSI, gedung kantor, K3

\section{PENDAHULUAN}

Bangunan gedung merupakan aset yang perlu dikelola dengan baik agar dapat digunakan dan dimanfaatkan secara optimal melalui penerapan manajemen aset untuk meningkatkan layanannya. Manajemen aset adalah ilmu dan seni dalam pengelolaan kekayaan yang perlu dilaksanakan sesuai dengan siklus aset yang diawali dengan proses perencanaan hingga pengahapusan atau pembaharuan, secara efektif dan efisien (Sugiama, 2013). Pengelolaan aset bangunan gedung seperti pengelolaan aset infrastuktur dimana kinerja aset dengan siklus pada tahap operasi dan pemeliharaan yang baik akan menghasilkan peningkatan efisiensi biaya dan memberikan efektivitas yang lebih lama dalam operasi, yang berarti keuntungan biaya pengadaan baru dapat ditangguhkan dan aset dapat digunakan lebih lama (Priyatiningsih dan Mei, 2019).

Gedung kantor adalah suatu fasilitas untuk menunjang berbagai aktifitas kegiatan pegawai perkantoran. Ruang kerja pada gedung perkantoran umumnya tidak berpindah-pindah, dan telah dilengkapi ruang-ruang fasilitas penunjang seperti untuk ruang arsip, ruang mesin, kantin dan ruang penunjang lainnya. Sehingga, perlu diperhatikan keamanan dan kenyamanan gedung. Dapat disadari atau tidak bahwa bekerja di dalam bangunan gedung juga berpotensi menjadi sumber atau mengandung bahaya karena menjadi tempat untuk melakukan banyak aktivitas. Pada saat sedang melakukan pekerjaan atau aktivitas, kemungkinan berpotensi terjadinya kecelakaan kerja yang berakibat fatal. Dengan hal tersebut bangunan gedung kantor sebagai salah satu tempat kerja para karyawan, tidak terlepas dari berbagai potensi bahaya lingkungan kerja yang dapat mempengaruhi keselamatan dan kesehatan.

Keselamatan dan Kesehatan Kerja (K3) adalah upaya perlindungan dari semua potensi yang dapat menimbulkan bahaya (Putera \& Harini, 2017). Bahaya yang dapat timbul dari bangunan gedung diantaranya bahaya listrik, pencahayaan, tata letak, dan lain sebagainya. Program K3 dapat mewujudkan rasa aman dan nyaman dalam bekerja, selain itu juga dapat meningkatkan kinerja aset bangunan seperti kondisi fisik, fungsional, utilitas dan keuangan. Penerapan K3 sangat penting terutama pada aset bangunan gedung, karena akan menekan risiko yang timbul dari 
rusaknya aset bangunan. Hal ini akan mempengaruhi kinerja aset bangunan, jika aset bangunan dalam kondisi rusak maka aset tidak dapat difungsikan dan dapat berpengaruh pada operasional bangunan gedung. Setiap bangunan tentunya memiliki tingkat risiko dan bahayanya masing-masing tidak terkecuali bangunan gedung kantor seperti objek bangunan Bale Wiwitan. Diharapkan dengan mengetahui tingkat penerapan program K3 berdasarkan Building Safety Index pada aset bangunan gedung maka akan menekan risiko dan dampaknya adalah efisiensi biaya. Penelitian ini bertujuan untuk mengetahui tingkat penerapan program K3 berdasarkan Building Safety Index pada aset gedung Bale Wiwitan Tasikmalaya.

\section{METODE}

Penelitian dilaksanakan dengan unit analisis gedung Bale Wiwitan yang berada di Jalan Noenoeng Tisnasaputra Nomor 5, Kelurahan Kahuripan, Kecamatan Tawang, Kota Tasikmalaya dengan koordinat 7²1'13"LS dan $108^{\circ} 13^{\prime} 43^{\prime \prime} B T$. Penelitian ini dimulai dari Bulan April sampai Bulan Agustus 2020. Penelitian ini menerapkan pendekatan kuantitatif dan kualitatif, dengan metode survei (Sugiama, 2008). Penelitian ini menggunakan populasi dengan total pengelola sebanyak 11 (sebelas) orang. Penelitian ini menggunakan sampel yang merupakan bagian kuantitas dan karakteristik yang terdapat pada populasi (Sugiyono, 2017). Teknik pengambilan sampel yang digunakan dalan penelitian ini yaitu sampling jenuh karena semua populasi digunakan sebagai sampel. Maka dari itu peneliti memilih teknik sampling jenuh karena jumlah populasi yang relatif kecil. Teknik pengumpulan data pada penelitian ini dilakukan menggunakan teknik observasi, wawancara, kuesioner dan studi pustaka.

1. Observasi.

Observasi digunakan untuk mengumpulkan data melalui pengamatan langsung di lapangan untuk memperoleh gambaran mengenai program K3 pada gedung Bale Wiwitan.

2. Wawancara.

Wawancara digunakan untuk memperoleh informasi dengan melakukan tanya jawab langsung terhadap pengelola Bale Wiwitan dalam mengumpulkan data. Dalam kondisi pandemik ini kami melakukan wawancara dengan melakukan penyesuaian dan tetap memperhatikan protokol kesehatan yang dianjurkan.

3. Kuesioner.

Kuesioner dilakukan dengan memberikan seperangkat pernyataan mengenai program K3 kepada responden untuk mempeoleh data. Penelitian ini menggunakan intrumen yang dimaksudkan untuk menghasilkan data yang akurat yang disajikan dalam google formulir dengan menggunakan skala likert. Metode ini digunakan untuk memperoleh data tentang persepsi penerapan K3 berdasarkan Building Safety Index (BSI).

4. Studi Pustaka

Studi pustaka digunakan dalam pengumpulan data yang berhubungan dengan penerapan program K3 aset bangunan, khususnya gedung kantor. Aspek kinerja keselamatan dan kesehatan bangunan harus diperhatikan selama siklus hidupnya untuk meningkatkan kualitas hidup penghuninya. Indikator-indikator tersebut dibahas dalam BSI (Rajali, 2016) yaitu arsitektur, building service, dan external environment.

Untuk mengetahui tingkat penerapan program K3 berdasarkan BSI, maka dibuatlah suatu bagan alir proses penelitian mulai dari awal hingga akhir dan diperoleh suatu kesimpulan. Penjelasan mengenai diagram alir penelitian yang dilaksanakan dapat dilihat pada bagan alir pada gambar 1 berikut.

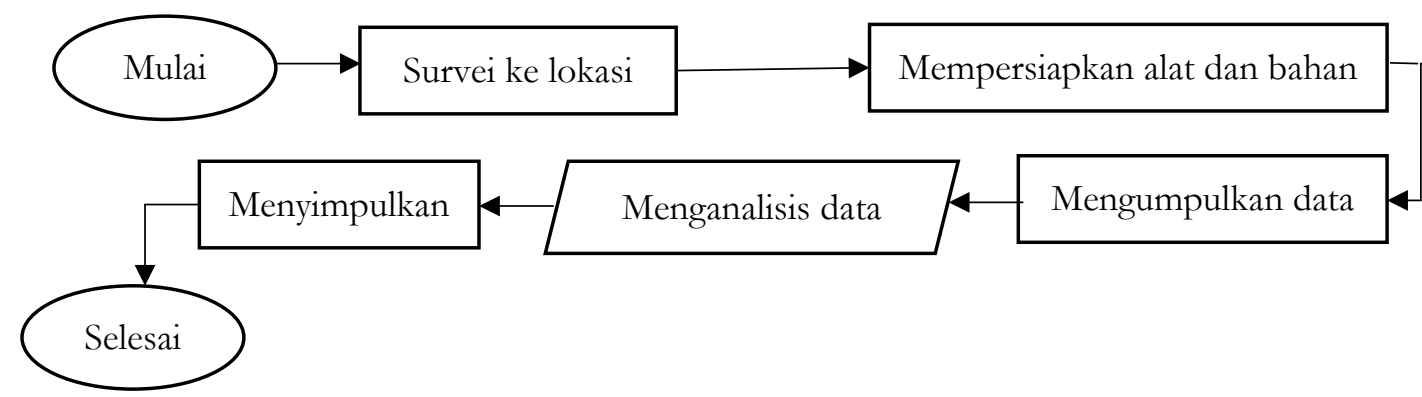

Gambar 1. Diagram Pelaksanaan Penelitian 


\section{HASIL DAN PEMBAHASAN}

Aset Gedung Bale Wiwitan Tasikmalaya dibangun sekitar tahun 1996/1997 yang memiliki luas tanah \pm 1,7 Ha dan luas bangunan $2.089 \mathrm{~m} 2$. Gedung kantor ini dibangun melalui proses Ruislaag Kantor Kota Administratif (Kotif) lama yang berada di Jalan Oto Iskandar Dinata Tasikmalaya, dengan pihak H. Amas Mupreni. Kantor Kotif ini di peruntukan untuk Kantor Walikota. Setelah Kantor Walikota Tasikmalaya dipindahkan ke Jalan Letnan Harun No. 1 Tasikmalaya, bangunan gedung ini berubah nama menjadi Bale Wiwitan. Gedung Bale Wiwitan ini sekarang menjadi tempat kantor dinas yaitu Dinas Pekerjaan Umum dan Penetaan Ruang (DPUPR) dan Dinas Perumahan Rakyat dan Kawasan Permukiman (DPRKP). Masih dalam satu area dengan gedung Bale Wiwitan terdapat Dinas Lingkungan Hidup. Aset gedung Bale Wiwitan Tasikmalaya awalnya merupakan aset milik Kotif. Setelah terbentuk Pemerintah Kota (Pemkot) Tasikmalaya pada tahun 2001, aset gedung Bale Wiwitan menjadi milik Pemkot Tasikmalaya. Kepemilikan aset bangunan Bale Wiwitan ini tercatat di KIB DPUPR. Pada tahun 2017 dilakukan rehabilitasi pada gedung Bale Wiwitan, sehingga tampak depan gedung Bale Wiwitan dapat dilihat pada gambar 2 berikut.

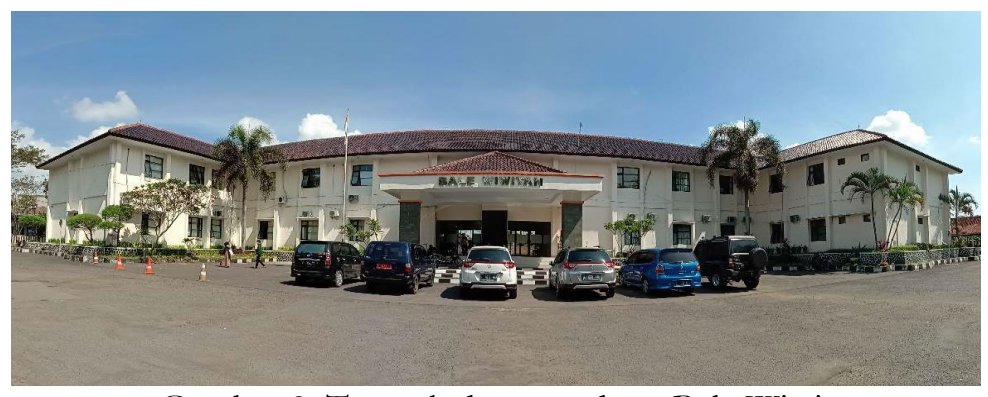

Gambar 2. Tampak depan gedung Bale Wiwitan

Aset bangunan gedung Bale Wiwitan Tasikmalaya termasuk dalam klasifikasi aset Real Estate and Facilities, hal ini merujuk pada teori yang dikemukan oleh Campbell (2011). Pembangunan gedung Bale Wiwitan bertujuan untuk memenuhi kebutuhan masyarakat dan menyediakan layanan pendukungnya agar dapat beroperasi secara efektif yang sesuai dengan tujuan manajemen aset menurut Hastings (2010). Dalam pengoperasian aset bangunan Bale Wiwitan pasti dihadapkan dengan kejadian tidak terduga yang dapat menimbulkan risiko, sehingga program K3 perlu diterapkan pada aset bangunan ini.

Tingkat Penerapan Program K3 pada aset bangunan kantor Bale Wiwitan diukur melalui hasil kuesioner yang telah dibagikan. Dari hasil kuesioner terdapat 11 responden pengelola gedung, dimana kuesioner ini mengandung butirbutir pernyataan berdasarkan teori Building Safety Index (BSI). Kriteria dan hasil pengukuran menggunakan skala likert dapat dilihat pada tabel 2. berikut.

Tabel 1. Kriteria pengukuran

\begin{tabular}{ll}
\hline Skala & Kriteria \\
\hline $1,0-1,8$ & Sangat buruk \\
$1,9-2,4$ & Buruk \\
$2,5-3,3$ & Cukup \\
$3,4-4,4$ & Baik \\
$4,3-5,0$ & sangat baik \\
\hline
\end{tabular}

Berikut ini merupakan pengukuran dari setiap dimensi Building Safety Index (BSI).

a. Arsitektur

Arsitektur mengacu pada konfigurasi tata letak dan disposisi bangunan, yang ditambahkan untuk memberikan lingkungan yang lebih besar serta detail desain terbaik jalur evakuasi, titik akses, struktur, tahan api, konstruksi, bahan bangunan, fungsi ruangan. Fokus arsitektur tidak hanya pada aspek estetika, tetapi harus dikombinasikan dengan solusi atau gaya struktural yang harus melekat pada ruang di mana kegiatan tertentu dapat terjadi, aman, nyaman dan efisien. Hasil kuesioner dari setiap pernyataan indikator disajikan pada tabel 1. 
Tabel 2. Dimensi arsitektur

\begin{tabular}{lllllll}
\hline \multicolumn{1}{c}{ Pernyataan/Pertanyaan } & $\mathbf{1}$ & $\mathbf{2}$ & $\mathbf{3}$ & $\mathbf{4}$ & $\mathbf{5}$ & Rata-rata \\
\hline $\begin{array}{l}\text { Kantor Bale Wiwitan memiliki aksesibilitas yang mu- } \\
\text { dah dijangkau }\end{array}$ & 0 & 0 & 1 & 8 & 2 & 4,09 \\
$\begin{array}{l}\text { Kantor Bale Wiwitan memiliki sistem struktur } \\
\text { bangunan yang baik }\end{array}$ & 0 & 2 & 4 & 4 & 1 & 3,36 \\
$\begin{array}{l}\text { Kantor Bale Wiwitan memiliki kontruksi bangunan } \\
\text { yang tahan api }\end{array}$ & 0 & 2 & 6 & 3 & 0 & 3,09 \\
$\begin{array}{l}\text { Kantor Bale Wiwitan memiliki ruangan-ruangan yang } \\
\text { digunakan sesuai dengan fungsinya }\end{array}$ & 0 & 3 & 7 & 0 & 1 & 2,91 \\
$\begin{array}{l}\text { Kantor Bale Wiwitan memiliki bahan bangunan yang } \\
\text { baik }\end{array}$ & 0 & 1 & 7 & 2 & 1 & 3,27 \\
\hline Rata-rata dimensi arsitektur & & & & & 3,35 \\
\hline
\end{tabular}

Dari hasil pengukuran diatas, dapat disimpulkan bahwa rata-rata dimensi arsitektur adalah 3,35 dan menurut skala likert dapat dikatakan baik.

b. Building Service

Building service, terdiri dari indikator instalasi listrik, penerangan, ventilasi udara, pendingin ruangan, layanan pipa \& sanitasi, dan jalur penghubung (tangga). Hasil kuesioner dari setiap pernyataan indikator disajikan pada tabel 3.

Tabel 3. Dimensi Building service

\begin{tabular}{|c|c|c|c|c|c|c|}
\hline Pernyataan/Pertanyaan & 1 & 2 & 3 & 4 & 5 & Rata-rata \\
\hline $\begin{array}{l}\text { Kantor Bale Wiwitan memiliki jalur evakuasi sebagai anti- } \\
\text { pasi terhadap bencana }\end{array}$ & 1 & 1 & 8 & 1 & 0 & 2,82 \\
\hline Kantor Bale Wiwitan memiliki instalasi listrik yang baik & 0 & 2 & 6 & 3 & 0 & 3,09 \\
\hline $\begin{array}{l}\text { Kantor Bale Wiwitan memiliki lampu penerangan yang } \\
\text { baik di seluruh ruangan }\end{array}$ & 0 & 1 & 7 & 2 & 1 & 3,27 \\
\hline Kantor Bale Wiwitan memiliki ventilasi udara yang baik & 0 & 0 & 7 & 3 & 1 & 3,45 \\
\hline Kantor Bale Wiwitan memiliki sanitasi yang baik & 0 & 2 & 6 & 2 & 1 & 3,18 \\
\hline $\begin{array}{l}\text { Kantor Bale Wiwitan memiliki pendingin ruangan di se- } \\
\text { tiap ruangan yang baik }\end{array}$ & 0 & 1 & 5 & 5 & 0 & 3,36 \\
\hline Kantor Bale Wiwitan memiliki jalur penghubung (tangga) & 0 & 0 & 6 & 4 & 1 & 3,55 \\
\hline $\begin{array}{l}\text { Kantor Bale Wiwitan memiliki pelayanan panggilan da- } \\
\text { rurat di sekitar lokasi }\end{array}$ & 1 & 2 & 7 & 1 & 0 & 2,73 \\
\hline $\begin{array}{l}\text { Kantor Bale Wiwitan memiliki risiko bahaya rawan pencu- } \\
\text { rian dan bencana alam }\end{array}$ & 0 & 0 & 7 & 3 & 1 & 3,45 \\
\hline Rata-rata dimensi building service & & & & & & 3,21 \\
\hline
\end{tabular}

Dari hasil pengukuran diatas, dapat disimpulkan bahwa rata-rata dimensi building service adalah 3,21 dan menurut skala likert dapat dikatakan cukup.

c. External Environtment

External environment, indikator yang diukur adalah layanan darurat, bahaya eksternal, kepadatan, lokasi, dan kualitas udara segar. Hasil kuesioner dari setiap pernyataan indikator disajikan pada tabel 4.

Tabel 4. Dimensi external environtment

\begin{tabular}{|c|c|c|c|c|c|c|}
\hline Pernyataan/Pertanyaan & 1 & 2 & 3 & 4 & 5 & Rata-rata \\
\hline $\begin{array}{l}\text { Kantor Bale wiwitan memiliki alat komunikasi internal } \\
\text { di dalam bangunan seperti public addess, telepon keba- } \\
\text { karan }\end{array}$ & 0 & 1 & 5 & 5 & 0 & 3,36 \\
\hline $\begin{array}{l}\text { Kantor Bale wiwitan terletak di lingkungan yang bebas } \\
\text { banjir, tanah longsor, degrasi lingkungan dan polusi } \\
\text { udara. }\end{array}$ & 0 & 0 & 4 & 5 & 2 & 3,82 \\
\hline $\begin{array}{l}\text { Kantor Bale Wiwitan terletak di lingkungan yang pa- } \\
\text { dat penduduk }\end{array}$ & 0 & 1 & 7 & 3 & 0 & 3,18 \\
\hline Kantor Bale Wiwitan terletak di lokasi yang strategi & 0 & 1 & 5 & 4 & 1 & 3,45 \\
\hline $\begin{array}{l}\text { Kantor Bale Wiwitan terletak di lokasi dengan kuali- } \\
\text { tas udara yang segar }\end{array}$ & 0 & 0 & 5 & 5 & 1 & 3,64 \\
\hline Rata-rata dimensi external environment & & & & & & 3,49 \\
\hline
\end{tabular}


Dari hasil pengukuran diatas, dapat disimpulkan bahwa rata-rata dimensi external environment adalah 3,49 dan menurut skala likert dapat dikatakan baik.

Hasil pegukuran kuesioner berdasarkan teori Building Safety Index (BSI) dapat menghitung tingkat penerapan K3 pada bangunan Bale Wiwitan. Tingkat penerapan tersebut dapat dihitung dari rata-rata setiap dimensi pada BSI, dapat dilihat pada tabel 8 . berikut.

Tabel 5. Tingkat Penerapan K3

\begin{tabular}{ll}
\hline \multicolumn{1}{c}{ Dimensi } & Skala Likert \\
\hline Arsitektur & 3,35 \\
Building service & 3,21 \\
External environment & 3,49 \\
\hline Rata-rata & $\mathbf{3 , 3 5}$ \\
\hline
\end{tabular}

Persentase yang tertinggi dari penelitian ini adalah pendekatan external environment dengan skor rata-rata 3,49. External environment sangat penting, hal ini berkaitan dengan situasi yang memungkinkan arus informasi yang membantu organisasi untuk mengkomunikasikan keinginan dan kebutuhan secara akurat sebagai bentuk memastikan keselamatan dan kesehatan penghuninya. Hal ini sebagai dasar untuk efisiensi sumber daya sehingga dapat menunjukan pada kinerja bangunan yang lebih baik. Sedangkan arsitektur memberikan kontribusi yang sedikit lebih kecil dibandingkan pendekatan external environment dengan rata-rata skor 3,35. Persentase ini menunjukan bahwa arsitektur merupakan bagian untuk mencapai kesuksesan suatu konstruksi karena berkaitan dengan arsitektur jangka panjang. Fokus arsitektur bangunan yang aman perlu menyertakan desain yang lebih baik, detail, serta estetika. Presentase terendah adalah pendekatan building service dengan skor rata-rata 3,21. Hasil ini menyatakan bahwa pelayanan bangunan ini harus diperhatikan, karena semakin baiknya pelayanan bagunan gedung maka akan semakin meningkatkan keamanan dan kesehatan.

Berdasarkan analisis tingkat penerapan program K3 berdasarkan BSI, rancangan program K3 yang dapat diterapkan pada aset Gedung Bale Wiwitan Tasikmalaya berdasarkan setiap dimensi BSI sebagai berikut.

a. Arsitektur

Arsitektur berhubungan dengan tata letak dan disposisi sebuah bangunan untuk memberikan lingkungan yang lebih besar serta detail desain terbaik untuk meningkatkan estetika. Dimensi arsitektur ini berkaitan dengan jalur evakuasi, titik akses, struktur, tahan api, konstruksi, bahan bangunan, fungsi ruangan. Aset Gedung Bale Wiwitan memiliki struktur rangka kaku (rigid frame) dengan pondasi telapak, kolom dan balok beton, dan penutup atap dengan genting. Pada dimensi arsitektur yang dapat diterapkan yaitu membuat sarana untuk keperluan keluar masuk yang aman, membagi ruangan sesuai dengan kebutuhan, menjaga kebersihan dan kerapihan tempat kerja dari barang-barang atau peralatan kantor, dan membuat jalur evakuasi atau perencanaan evakuasi untuk mengantisipasi jika terjadi bencana. Dalam pembagian ruangan yang digunakan harus sesuai dengan fungsinya, sehingga aset gedung dapat menciptakan rasa aman, nyaman, serta dapat meningkatkan kinerja aset gedung. Selain itu penyediaan sistem deteksi dan alarm kebakaran, serta penyediaan sistem pemadam kebakaran terdiri dari sistem hydrant kebakaran, sistem sprinkler kebakaran, sistem pengendalian asap, pencahayaan darurat dan tanda penunjuk arah dan pusat pengendali kebakaran.

b. Building service

Layanan bangunan yang aman, nyaman dan ramah lingkungan dalam pengoperasian gedung mengacu pada instalasi listrik, penerangan, ventilasi udara, pendingin ruangan, layanan pipa \& sanitasi, dan jalur penghubung (tangga). Penerangan aset gedung berasal dari lampu antifisial pada malam hari, sedangkan siang hari berasal dari sinar matahari. Dalam hal instalasi listrik, listrik disediakan oleh PLN dengan rangkaian listrik yang menggunakan alat pelindung yang dapat melindungi peralatan listrik agar tidak mudah rusak dan konslet jika terkena air. Dimensi building service yang dapat diterapkan yaitu membangun pelayanan panggilan darurat dan membuat jalur evakuasi sebagai antisipasi terhadap bencana. Hal ini dapat dilengkapi dengan rambu dan simbol yang dapat menginformasikan kepada pekerja tentang bahaya yang akan timbul. Penyediaan tanda (signage) dan sarana/jalur evakuasi dalam bangunan yang tidak terhalang dan terjaga kondisinya, sehingga dalam keadaan darurat evakuasi menuju tempat berhimpun (assembly point) dapat dilakukan dengan selamat dan tanpa hambatan. Hal tersebut, dapat mengantisipasi bahaya dan meminimalisir risiko yang dapat terjadi di Gedung Bale Wiwitan. Selain itu, mesin pendingin ruangan (AC) yang dipasang di ruang kerja perlu perbaikan agar ruangan terasa nyaman untuk mendukung kegiatan operasinya. 


\section{c. External environment}

Langkah-langkah keselamatan dan kesehatan harus mencakup perlindungan terhadap tambahan bahaya yang ditimbulkan oleh lingkungan eksternal. Dimensi external environtment meliputi layanan darurat, bahaya eksternal, kepadatan, lokasi, dan kualitas udara segar. Aset Gedung Bale Wiwitan berada di lokasi yang cukup strategis dengan kualitas udara yang segar, lingkungan yang bebas banjir, tanah longsor dan polusi. Pada dimensi ini yang dapat diterapkan yaitu menciptakan lingkungan yang asri dengan kualitas udara yang segar. Sehingga dapat terhindar dari polusi udara meskipun berada pada lingkungan dengan kepadatan penduduk yang padat. Selain itu, alat komunikasi internal di dalam bangunan seperti public address, dan telepon kebakaran perlu disiapkan untuk mengkomunikasikan kebutuhan secara akurat dan memastikan kesehatan dan keselamatan penghuninya.

\section{SIMPULAN}

Berdasarkan hasil penelitian dan pembahasan yang telah dijelaskan, maka dapat disimpulkan bahwa:

1. Tingkat penerapan program K3 berdasarkan Building Safety Index (BSI) di gedung Bale Wiwitan terdiri dari arsitektur, building service, dan external environment. Tingkat penerapan K3 berdasarkan BSI menghasilkan skor rata-rata 3,35 menurut skala Likert dapat dikategorikan dalam kelompok baik.

2. Pada dimensi arsitektur Gedung Bale Wiwitan yang dapat diterapkan yaitu pembagian ruangan yang digunakan harus sesuai dengan fungsinya, menjaga kebersihan dan kerapihan tempat kerja dari barang-barang atau peralatan kantor, membuat jalur evakuasi atau perencanaan evakuasi untuk mengantisipasi jika terjadi bencana, menyediakan sistem deteksi kebakaran, serta penyediaan sistem pemadam kebakaran.

3. Pada dimensi building service yang dapat diterapkan yaitu membangun pelayanan panggilan darurat, membuat jalur evakuasi sebagai antisipasi terhadap bencana, dan perbaikan pendingin ruangan di tempat kerja. Hal ini dapat meningkatkan kenyamanan, meminimalisir bahaya dan risiko.

4. Sedangkan pada dimensi external environtment yang dapat diterapkan pada aset Gedung Bale Wiwitan yaitu menciptakan lingkungan yang asri dengan kualitas udara yang segar. Sehingga dapat terhindar dari polusi udara meskipun berada pada lingkungan dengan kepadatan penduduk yang padat. Selain itu, alat komunikasi internal di dalam bangunan seperti public address, dan telepon kebakaran perlu disiapkan untuk mengkomunikasikan kebutuhan secara akurat dan memastikan kesehatan dan keselamatan penghuninya.

\section{UCAPAN TERIMAKASIH}

Terima kasih kepada DIPA Politeknik Negeri Bandung yang telah membiayai penelitian ini sesuai dengan Surat Perjanjian Pelaksanaan Program Kreativitas Mahasiswa (PKM) Polban tahun 2020.

\section{REFERENSI}

Campbell, John D., Andrew K.S. Joel McGlynn, 2011, “Asset Management Excellence: Optimizing Equipment Life-Cycle Decisions", Second Edition, CRC Press. Boca Raton.

Hastings, N. A. J, 2010, 'Physical Asset Management”, Springer. London.

Priyatiningsih, Katharina and Mei Sutrisno., 2019, "Road Infrastructure Asset Management Strategy", The Third International Conference on Innovation in Engineering Vocational Education (ICIEVE), Bandung, Indonesia. http://icieve.conference.upi.edu/2019

Putera, R. I, dan Harini, Sri., 2017, "Pengaruh Keselamatan dan Kesehatan Kerja (K3) terhadap Jumlah Penyakit Kerja dan Jumlah Kecelakaan Kerja Karyawan pada PT. Hanei Indonesia”, Jurnal Visionida. Vol. 3 (1):42.

Rajali, Amirul Rusydie., 2016, "Building Safety Index: Contributing Factor", Journal.

Sugiama, A Gima, 2013, “Manajemen Aset dan Pariwisata”, Edisi Pertama, Guardaya Intimarta. Bandung.

Sugiama, A Gima, 2008, "Metode Riset Bisnis dan Manajemen”, Guardaya Intimarta. Bandung.

Sugiyono, 2017, 'Metode Penelitian Bisnis Pendekatan Kuantitif, Kualitatif, Kombinasi, dan R\&D”, Alfabet. Bandung. 